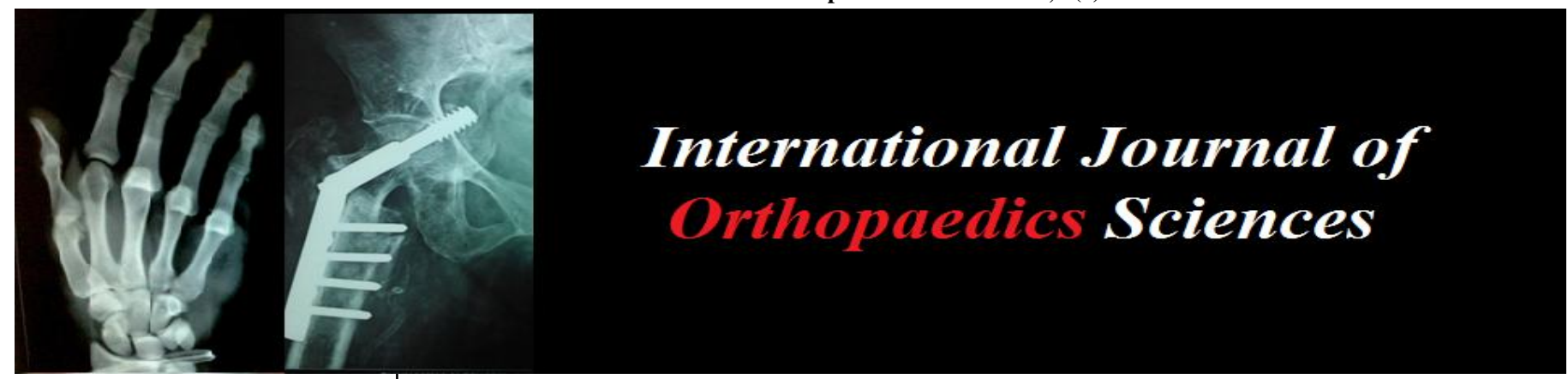

ISSN: $2395-1958$

IJOS 2018; 4(1): 1133-1141

(C) 2018 IJOS

www.orthopaper.com

Received: 20-11-2017

Accepted: 22-12-2017

Dr. Aravindan Karunakaran M. S Ortho, D. Ortho Assistant Professor, Department of Orthopaedics, Chengalpattu Medical College Hospital, Chengalpattu, Tamilnadu, India

Dr. Samuel Gnanam Rajamani Associate Professor, Department of Orthopaedics, Chengalpattu Medical College Hospital, Chengalpattu, Tamilnadu, India

\section{A prospective study of locking plate fixation in tibial plateau fractures}

\section{Dr. Aravindan Karunakaran and Dr. Samuel Gnanam Rajamani}

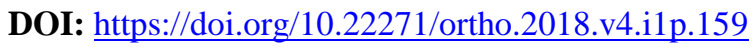

\section{Abstract}

Introduction: Originally described as the fender fracture tibial plateau fractures resulted primarily from low-energy pedestrian versus car bumper accidents. The majority of tibial plateau fractures reported in the recent literature have resulted from high-speed motor vehicle accidents and falls from a height. Injuries to the tibial plateau occur as a result of a force directed either medially (valgus deformity, the classic "bumper fracture") or laterally (varus deformity), an axial compressive force or both an axial force and a force from the side. Locking Compression plates have become and imminent tool in the management of these complex fractures.

Aim: The aim of the study is to analyze prospectively by clinical, radiological and functional methods the results of open/closed reduction and internal fixation of closed tibial plateau fractures treated by Locking Compression Plates.

Method: This is a prospective study conducted in Chengalpattu Medical College and Hospital, Chengalpattu. Twenty patients who satisfied the following criteria were included in our study. Depending on the type of fracture and severity of soft tissue injury all the patients were stabilized initially and closed or open reduction of the fracture done and fracture stabilized with locking compression plate.

Discussion and Conclusion: The results were analyzed both clinically and radiologically using the Knee scoring system by Hospital for Special Surgery. Results based on Knee Scoring System, Hospital for Special Surgery (HSS) we had excellent result in 10 cases, good result in 7 cases, fair result in 3 cases and we had no poor result.

From our study, we conclude that, Open/closed reduction and internal fixation of closed tibial plateau fractures with locking compression plate is an effective method of treatment provided there is no extensive soft tissue injury. Locking compression plate provides good angular stability with its triangular reconstruction principle.

Keywords: Tibial plateau fracture, locking compression plate, functional outcome

\section{Introduction}

A proper function of the knee is important in walking, running and in most activities. Injuries of the knee must be treated properly to maintain a good knee function. In the last few decades, rapid industrialization and the fast pace of life have brought both comforts and catastrophe like road traffic accidents crippling many lives. Fractures of the tibial plateau involve the knee, which is a major weight bearing joint, and these are serious injuries, which frequently result in functional impairment. The goals in treating fractures of the tibial plateau are to restore the joint space, mechanical alignment of the limb, to achieve optimal healing of bone, tendon and ligaments, and to allow painless full range of motion of the knee. The optimal treatment of tibial plateau fractures has been a source of controversy for a long time. They were managed both by operative and non-operative methods.

In the early 1960s, there was a great reluctance towards operative management of these fractures because of high incidence of infection, non-union, malunion, inadequate fixation and lack of proper instrument, implant as well as antibiotics. Then, the traditional management of displaced fractures was along the principle of Watson Jones \& John Charnley. This comprised of skeletal traction, manipulation of fracture and external immobilization in the form of casts and cast bracings. These methods however, met with problems like deformity, shortening, prolonged bed rest, knee stiffness, angulation, joint incongruity, malunion, quadriceps wasting, knee instability and post traumatic arthritis.
Dr. Aravindan Karunakaran M. S Ortho, D. Ortho Assistant Professor, Department of Orthopaedics, Chengalpattu Medical College Hospital, Chengalpattu, Tamilnadu, India 
The trend of open/closed reduction and internal fixation has become evident in the recent years with good results being obtained with locking compression plates.

Elderly patients with severe osteoporosis add further to the difficulties in management of fractures around knee which requires restoration of articular congruency for painless free movements of joint. Loss of stable fixation in osteoporotic bones is of great concern in such elderly patients. Locking compression plates with its innumerous advantage is of great use in such circumstances. In this study we are analyzing the results of open/closed reduction and internal fixation of these fractures with locking compression plates.

\section{Aims and Objectives}

The aim of the study is to analyze prospectively by clinical, radiological and functional methods the results of open/closed reduction and internal fixation of closed tibial plateau fractures treated by Locking Compression Plates, at Chengalpattu Medical College Hospital, Chengalpatu, between May 2015 to April 2017.

\section{Materials and Methods}

This is a prospective study conducted in Chengalpattu Medical College and Hospital, Chengalpattu, from May 2015 to April 2017. Twenty patients who satisfied the following criteria were included in the study out of which 4 were type II (20\%), 1 was type IV(5\%), 9 were type V (45\%) and 6 were type VI $(30 \%)$ tibial plateau fractures. We included Tibial Plateau fractures in adults which were closed and Schatzker's Type I to Type VI. We excluded Paediatric fractures, open fractures and late cases with infection and Joint stiffness. Patients are received in the emergency room and initial stabilization done. A thorough history is elicited about the mode of injury and temporary splinting of the limb done. After the initial X-rays, patients were managed with knee aspiration for haemarthrosis if necessary and Above Knee slab. Skeletal traction was applied in 2 patients who had Tscherne's grade III injuries, head injury and delay in the definitive treatment due to medical conditions.

\section{Pre-Operative Planning and Preparation}

Fractures are classified with the help of radiographs according to the Schatzkers Classification. Pre-operative calculation was done on radiographs to ascertain the size of the plate, accurate size of locking, cortical and cancellous screws after subtraction of the magnification factor. The limb to be operated was shaved and prepared the day before scheduled surgery. One gram of intravenous third generation cephalosporin was injected previous night and early morning on the day of surgery.

\section{Surgical Procedure}

Patient is positioned supine with a small sand bag under the gluteal region and a sterile rolled pillow under the affected knee, which will provide the capability to flex the knee to 90 degrees. Surgery is done with tourniquet. For fractures of the lateral condyle, anterolateral incision is made, starting just above the patella proximally and extending distally below the inferior margin of the fracture site. The incision provides good exposure, while avoiding skin complications. Fascial incision parallel to the anterior border of the iliotibial tract is done. The plane of dissection over the anterior patella should be below the fascia, which supplies blood to the prepatellar skin. If necessary for exposure, release of a portion or all of the iliotibial band from its insertion on the Gerdy tubercle is made. To expose the longitudinal fracture of the lateral condyle, the origin of the extensor muscles is stripped from the anterolateral aspect of the condyle. The horizontal limb of the incison is extended laterally from the the tibial tuberosity. Reflect the muscle origin laterally until the fracture line is exposed. A periosteal elevator is inserted well beneath the depressed articular fragments, and by slow and meticulous pressure, the articular fragments and compressed cancellous bone are elevated in one large mass. This produces a large cavity in the metaphysis that must be filled with bone. We prefer packing cancellous bone in to the defect. Bone can be obtained from the iliac crest. After the fragments are elevated and reduced, temporarily fix them with multiple Kirschner wires. Locking compression plate is used for fixation. The plate is applied to the anterolateral tibial condyle which is precontoured to conform to the condyle and proximal metaphysis. When properly contoured, it is secured to the condyle with appropriate locking/plain cancellous screws of sufficient length to engage the medial cortex. Locking/cortical screws are used to attach the plate to the shaft of the tibia which may be unicortical when locking screws are used. After stable fixation wound is closed in layers.

Locking compression plate is also used as LISS when minimally invasive surgery is done with closed reduction of the fragments under image intensifier control. Proximally a transverse incision is made about $3 \mathrm{~cm}$ in length along the tibial condyle. Gentle traction is given along the limb to reduce the fragments. Fracture reduction is checked with $\mathrm{C}$ arm. Periosteal elevator is used to raise the skin flap along the shaft of the tibia for the plate to slide in. Locking compression plate which was planned before is slided in from proximal to distal along the shaft. It is then temporarily fixed with Kirschner wires and postion again checked. Then the plate is then fixed with appropriate Locking/cancellous screws proximally and with locking/cortical screws to the shaft. Depending on the fracture configuration lateral/medial plating is done where there is more comminution and instability. In Schatzker type V and VI injury patterns if needed additional cannulated cancellous screws were applied along with the LCP fixation to provide stability to the other fragment.

Wound is closed in layers with a suction drain insitu. Suction drain maintained for 48 hours or until the drainage is minimal. Post operatively the limb is rested in a well-padded above knee slab. Intravenous third generation cephalosporin antibiotic is continued for 3 days post operatively and then orally for another 5 days. Static Quadriceps exercise started from day 1 as tolerated by the patient. Once the pain and the tension in the operated site comes down they are started on gentle assisted motion. By the end of first week patients are started on active range of motion. Suture removal done on $12^{\text {th }}$ day. Non-weight bearing crutch walking started before discharge. They are then reviewed once in every 4 weeks and check X-rays are taken to assess the progression of fracture union. Weight bearing is usually delayed up to $12-16$ weeks as these fractures are highly comminuted. All the patients are then assessed clinically and radiologically by Knee Scoring System by Hospital for Special Surgery.

\section{Results}

All the 20 patients were available for follow-up and they were followed up every month during the first 4 months and every 2 months during the first year. The minimum follow-up was 3 months and maximum was 15 months, mean follow-up being 7.38 months. The mean age was 41.35 yrs. It ranged from 22 years to 60 years. $80 \%$ of the cases were between $31-50$ years 
in $4^{\text {th }}$ and $5^{\text {th }}$ decade. Between 61 to 70 years no case was reported. There were 14 male and 6 female patients. 16 out of 20 cases were because of high-speed motor vehicle accidents 4 cases sustained the fracture due to fall from height. Of the 20 patients Right side was fractured in 12 cases and in 8 cases left was involved. Type Schatzker's was the majority which included 9 cases, Type VI being 6 cases, Type II 4 cases and Type IV 1 case. Tscherne's grading for soft tissue injuries in closed fractures was followed. We had 4 grade 0 injuries, 6 grade I, 7 grade II, and 3 grade III injuries. Pain was present post-operatively while walking in about 11 patients out of which 8 cases had mild pain and 3 cases had moderate pain. On analyzing the Range of movements 6 cases had full range of movements, 3 cases had up to 120 degrees, 4 had up to 110 degrees,

4 had 100 degrees of movement and 3 cases had less than 90 degrees of movement.

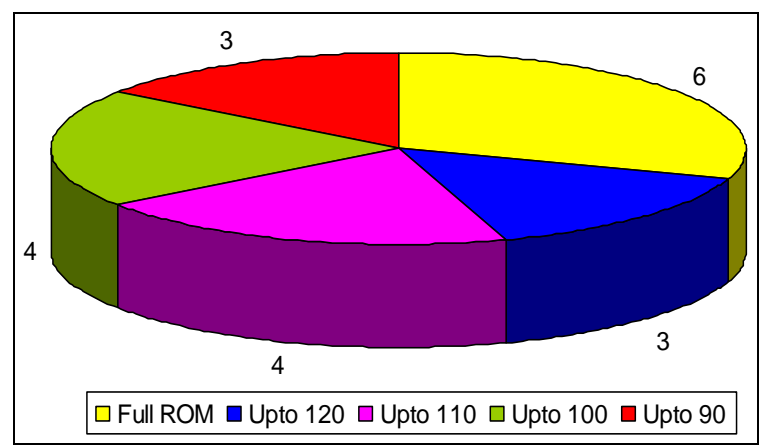

The results were analyzed both clinically and radiologically using the Knee scoring system by Hospital for Special Surgery.

Table : Results based on Knee Scoring System, Hospital for Special Surgery (HSS)

\begin{tabular}{|c|c|c|}
\hline Results & Number of Cases & Percentage \\
\hline Excellent & 10 & 50 \\
\hline Good & 7 & 35 \\
\hline Fair & 3 & 15 \\
\hline Poor & 0 & 0 \\
\hline
\end{tabular}

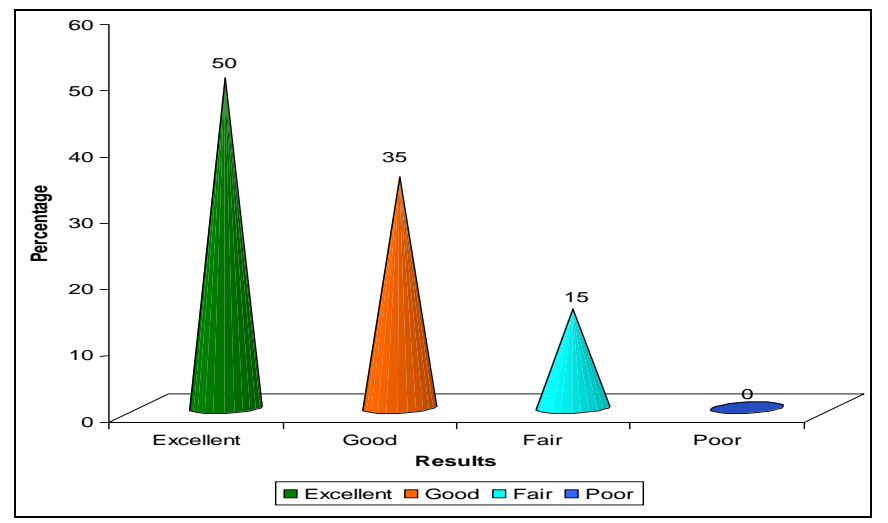

Analysing the overall results and scores and grouping them under Schatzker's type II, VI, V and VI.

Table : Results by Schatzker's Type

\begin{tabular}{|c|c|c|}
\hline Type & No. of Cases & HSS Score Average \\
\hline II & 4 & 85 \\
\hline IV & 1 & 89 \\
\hline V & 9 & 85 \\
\hline VI & 6 & 82 \\
\hline
\end{tabular}

\section{Complications}

1. Infection occurred in two cases; one had superficial infection that settled with appropriate antibiotics. Other case had deep infection which required wound debridement followed by broad spectrum intra venous antibiotic guided by the culture and sensitivity report for a prolonged period. The fracture united well in 24 weeks. No evidence of further infection after one year of follow up.

2. Pain-Mild pain while walking was present in 8 cases and moderate pain was present in 3 cases.

3. Knee stiffness-Less than 90 degrees of ROM was present in 3 cases. One case was with superficial wound infection where the mobilization was delayed and patient ended with 60 degrees of knee flexion. Two other case mobilization was not adequate and it led on to stiffness.

4. Articular incongruity-One case had significant articular incongruity of the medial tibial condyle, where there was a coronal split fracture of the medial tibial condyle.

\section{CASE 1: 22 Yr/Male, RTA, Type VI Schatzker Tibial Plateau Fracture, Right side}
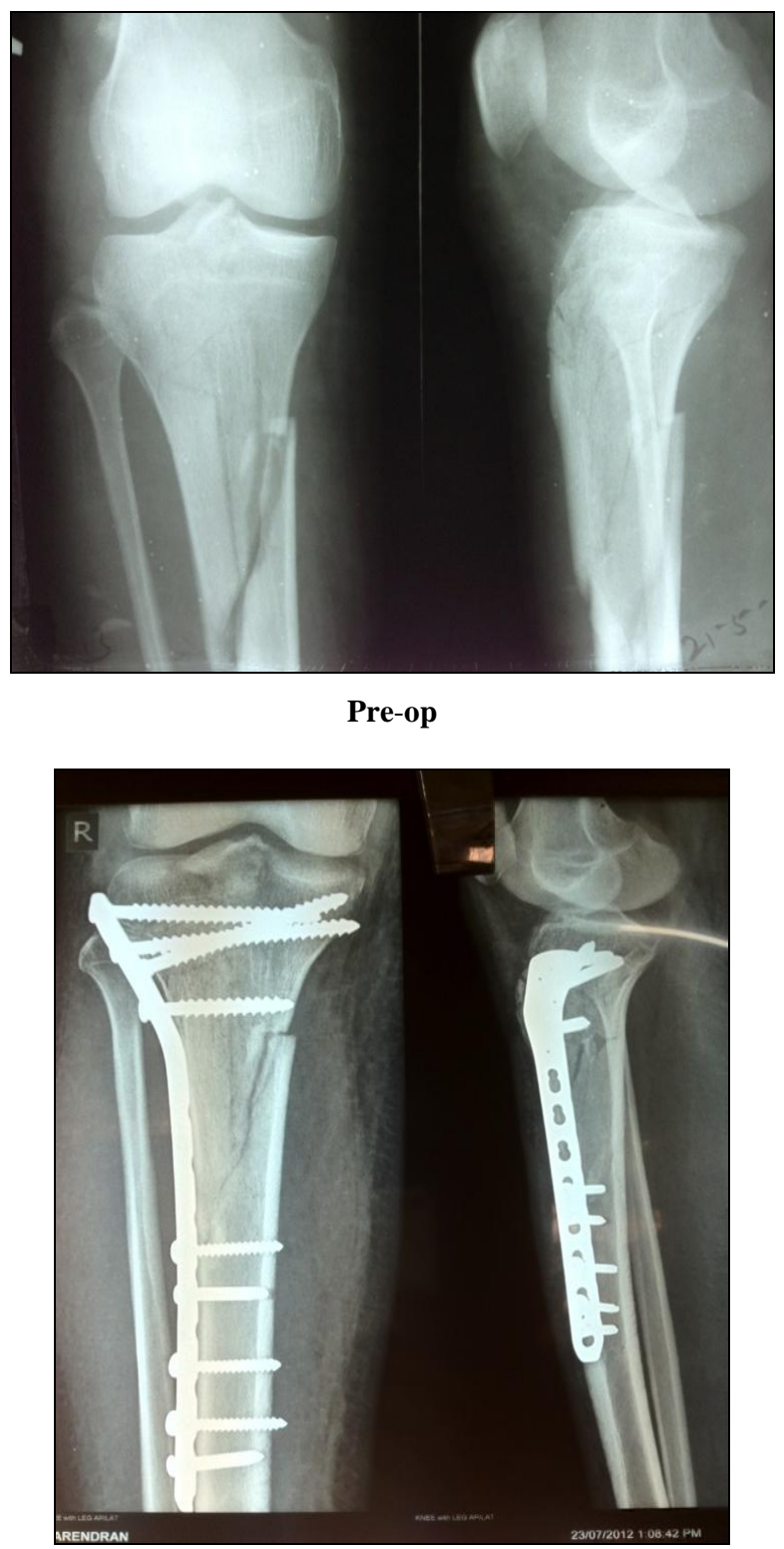

Post-op 


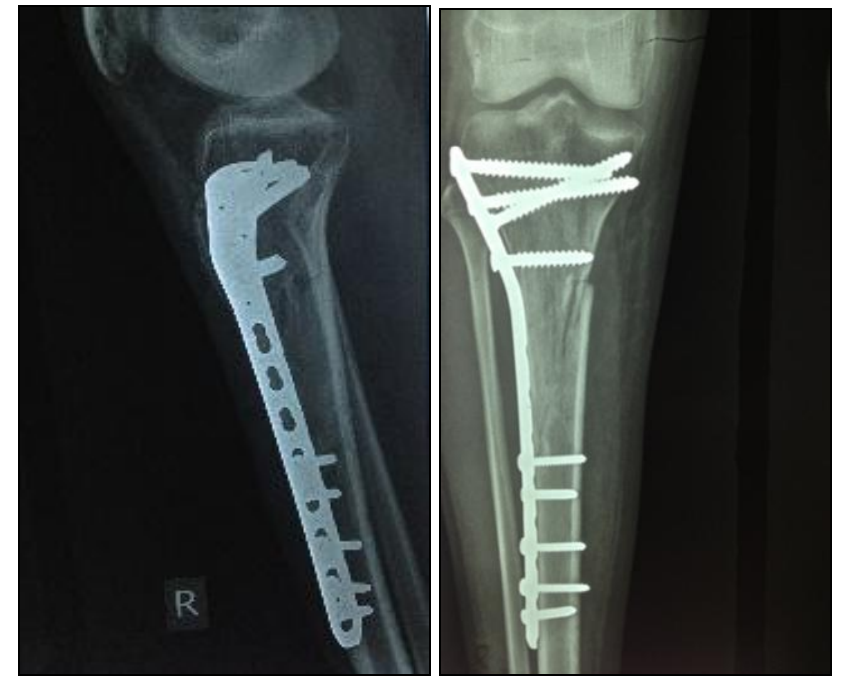

6 months

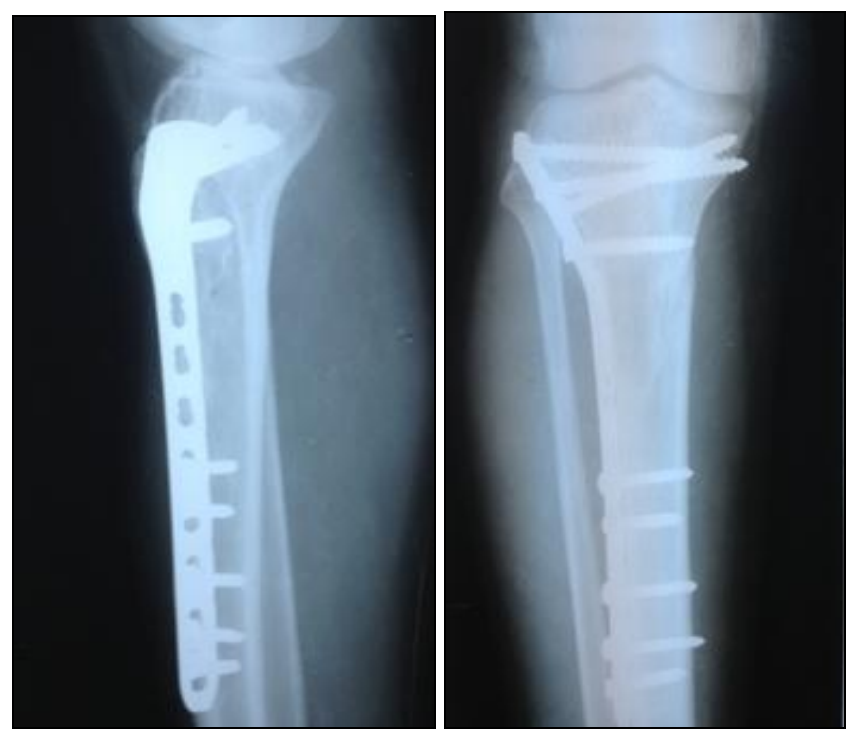

1 yr 3 months

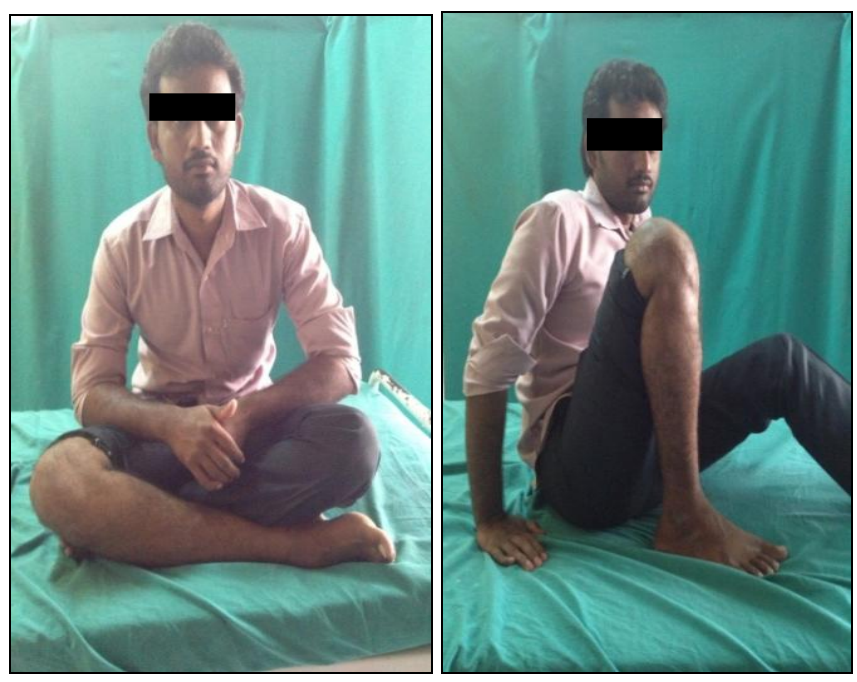

With Full Flexion of Knee

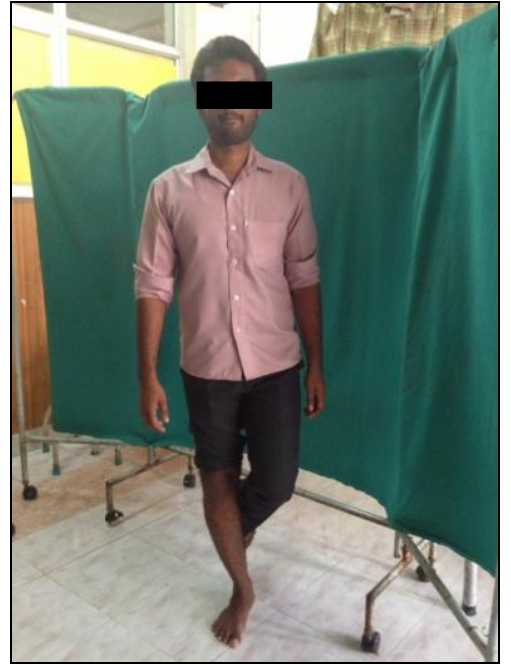

Full Weight Bearing

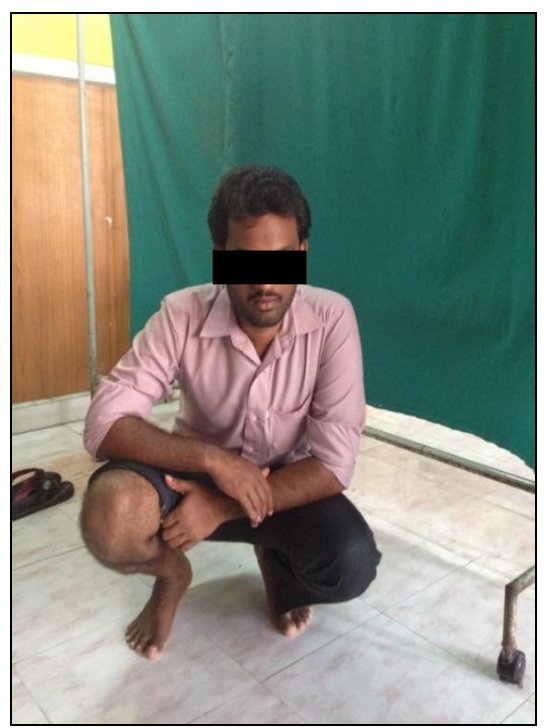

Able to Squat

Case 5: 39 Yr/Male, RTA, Type V Schatzker Tibial Plateau Fracture, Right side

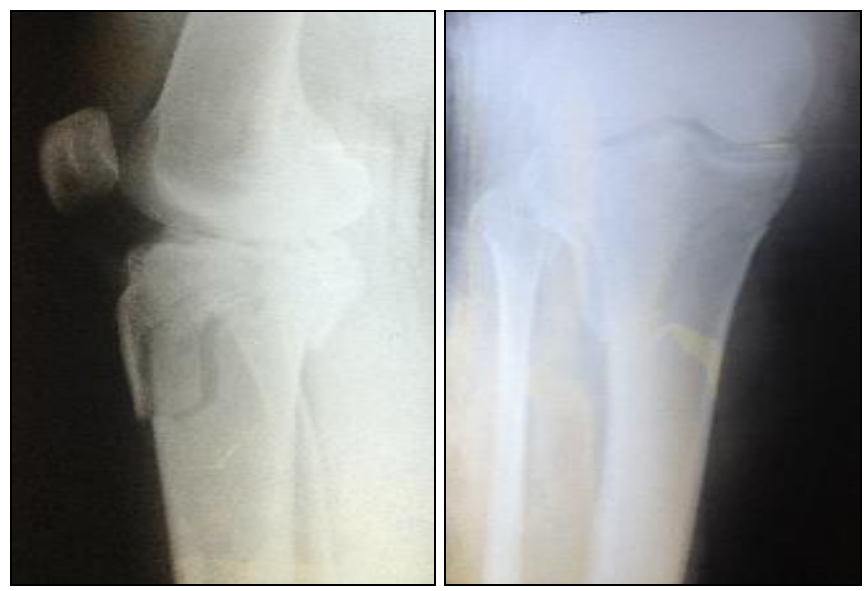

Post-op 


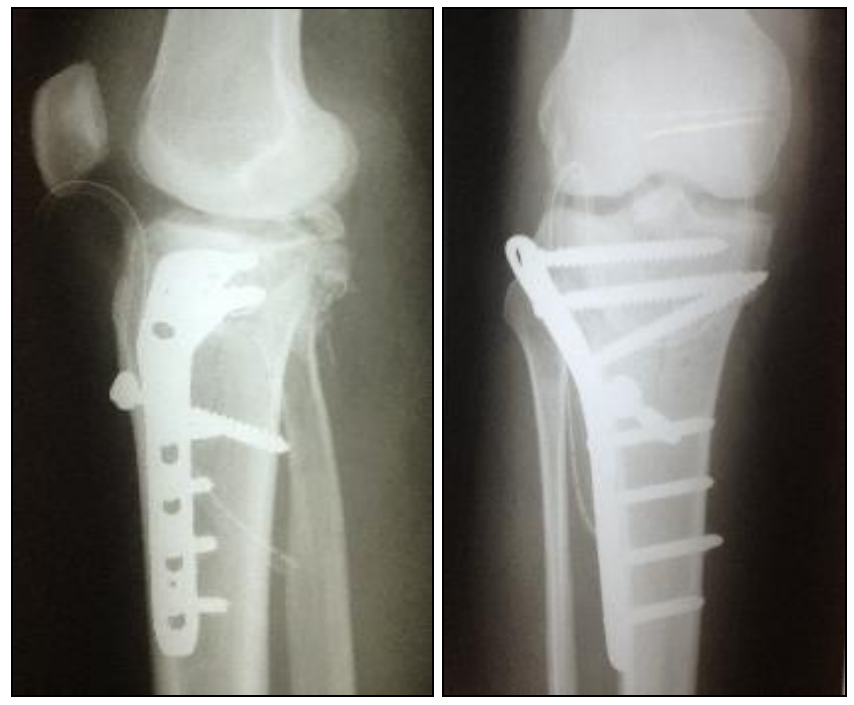

Pre-op

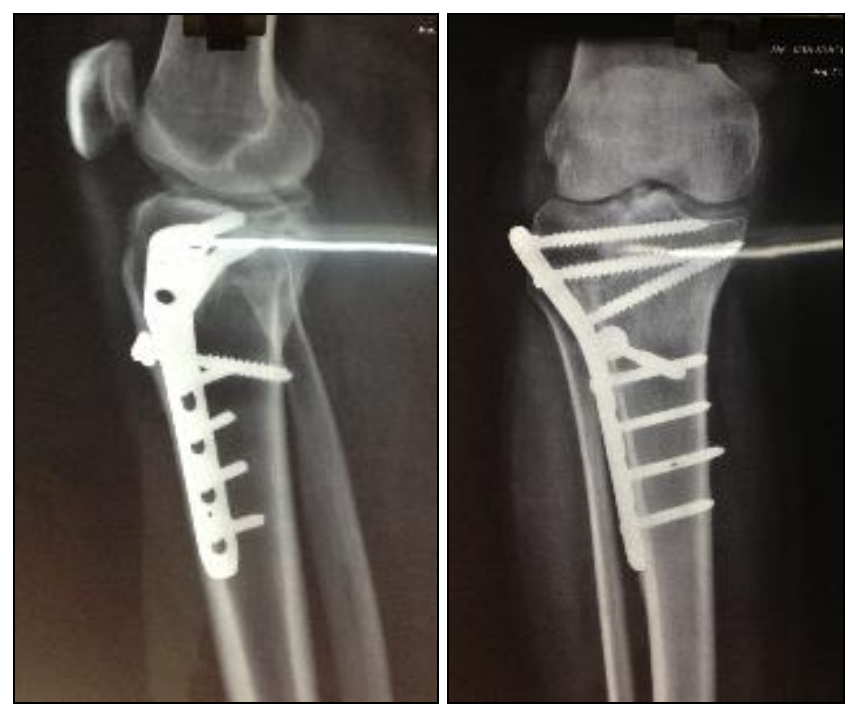

6 months

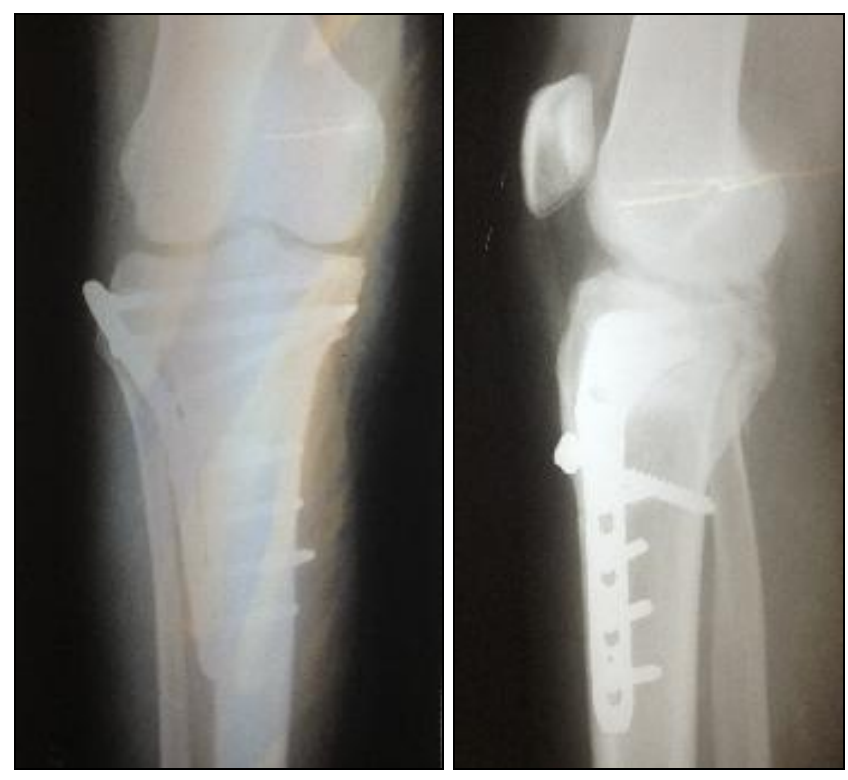

12 months

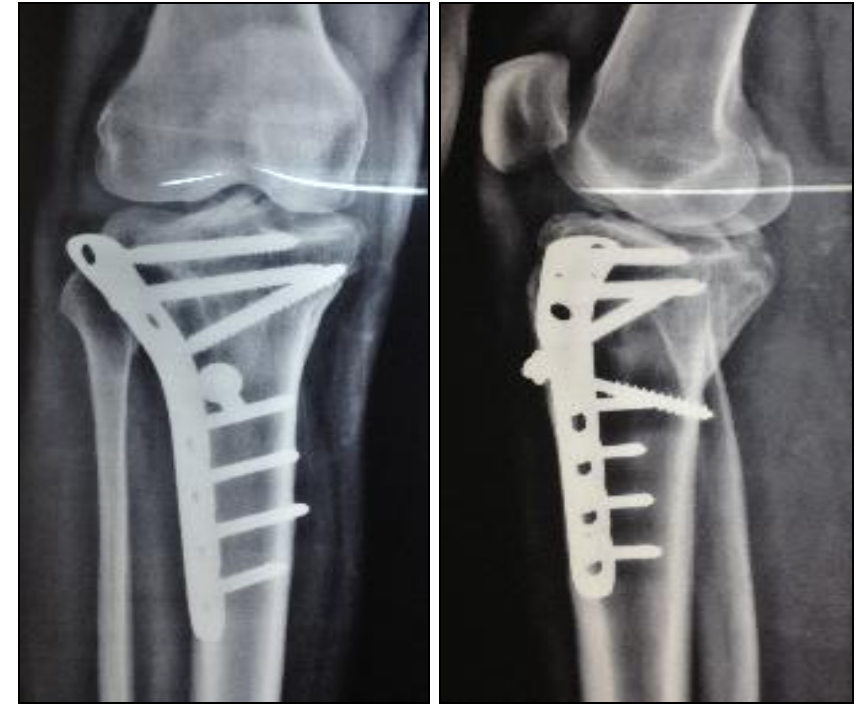

18 months

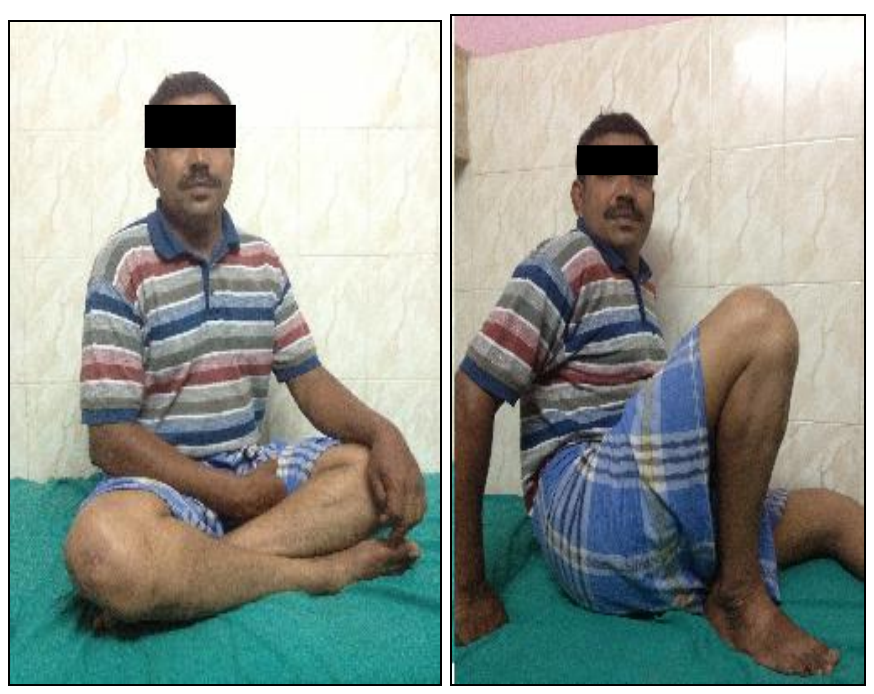

Sitting Cross legged with Excellent Knee Flexion

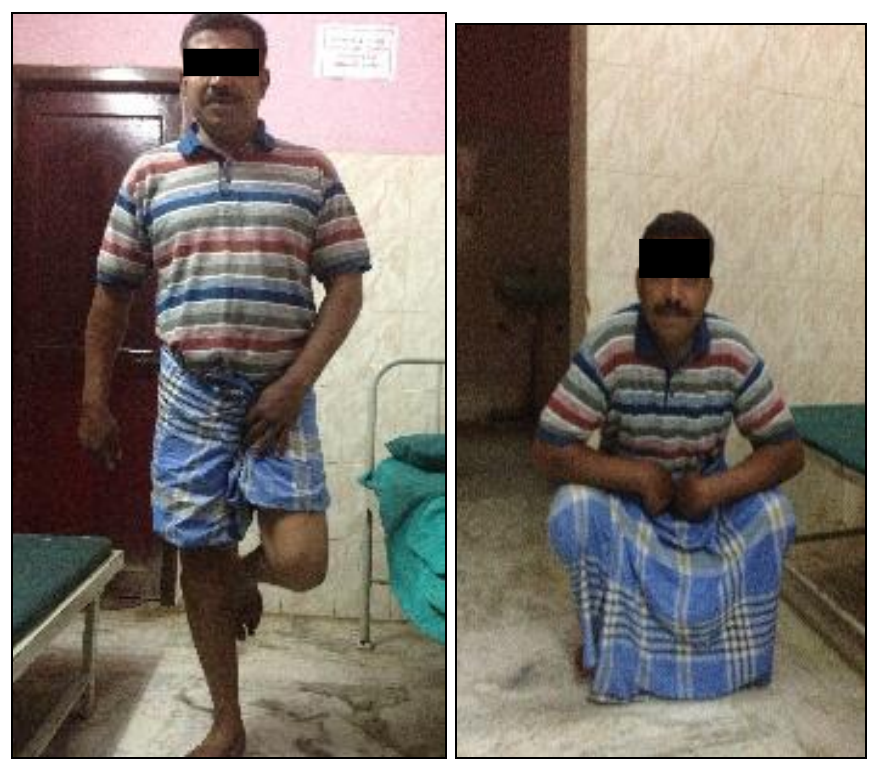

Full Weight Bearing and Squatting 


\section{Discussion}

Fractures of the tibial plateau have the potential to be devastating injuries especially when they have significant bony and soft tissue involvement and are displaced with knee instability and incongruity. The goals of treatment of proximal tibial articular fractures include restoration of articular congruity, axial alignment, joint stability, and functional motion. If operative treatment is chosen, fixation must be stable enough to allow early motion, and the operative technique should minimize wound complications.

Historically, closed treatment of displaced tibial plateau fractures including traction and immobilization resulted in unacceptably high rates of malunion and joint stiffness. With advancements in internal fixation principles, operative treatment modalities were explored but were often associated with high complication rates. Difficulties arose in finding a balance between adequate surgical exposure and protection of the compromised soft tissue environment. Anatomic reduction and stable fixation often required extensive exposure of both the medial and lateral aspects of the proximal tibia that led to problems with wound healing and infection in the compromised soft tissue environment. Because of these soft tissue problems, minimal internal fixation and external fixation techniques have been reported with some success. Problems with these minimally invasive techniques include inadequate reduction, unstable fixation, and pin tract complications.

Recent advancements in angle-stable locking plate technology has allowed for a new approach to these difficult fractures. Locking plates allow the surgeon to place a biomechanically stable internal fixator on the lateral side of the proximal tibia through a limited surgical exposure. This technique will potentially allow for anatomic reduction and stable internal fixation while minimizing soft tissue problems often associated with the subcutaneous medial border of the proximal tibia.

Age: Ehlinger $\mathrm{M}$ et al $^{[21]}$ in their series of 20 patients with tibial plateau fractures treated with locking compression plate fixation reported a mean age of 47 years. In our series of 20 patients, mean age was 41.35 years. Maximum number of patients $16(80 \%)$ were between the ages of 30-50 years. Being a high velocity injury it was found more commonly in active individuals.

Male to Female Ratio: Jackson A Lee et al $^{[28 \mathrm{a}]}$ in their study of 35 patients with Tibial Plateau fractures $23(65.7 \%)$ were males and $12(34.2 \%)$ were females. Ryan J Krupp et al ${ }^{[44]}$ in their series of 28 patients with Tibial Condyle fractures treated by Locking plate fixation, 14 patients (50\%) were males and 14 patients $(50 \%)$ were females. David P Barei et al ${ }^{[5]}$ had 23 (56\%) male patients and 18 (44\%) female patients.

In our series of 20 patients, 14 patients $(70 \%)$ were males and 6 patients $(30 \%)$ were females. Male preponderance was found in our study, probably because males sustained this high energy fractures more owing to their more active life style. As majority of the cases were caused by road traffic accidents in our study increased incidence of these fractures among males is explainable.

Mode of Injury: Ryan J Krupp et al ${ }^{[44]}$ in their series of 28 patients with Tibial Condyle fractures treated by Locking plate fixation, 22 patients $(78.5 \%)$ had sustained the fracture following a road traffic accident and 6 patients $(21.5 \%)$ had fall and sustained the fracture. Jackson a Lee et al ${ }^{[28 \mathrm{a}]}$ in their study of 35 patients had 28 cases $(68.3 \%)$ following a road traffic accident and 4 patients $(9.7 \%)$ following a fall and 3 other cases had other forms of injuries.

In our series of 20 patients, 16 patients $(80 \%)$ sustained the fracture following a road traffic accident and 4 patients (20\%) had a fall and sustained the fracture. It clearly demonstrates that these complex fractures occur a high velocity road traffic accidents in young individuals and in cases of elderly population can occur following a fall due to the osteoporotic nature of the bone.

Fracture Type: Ehlinger $\mathrm{M}$ et al ${ }^{[21]}$ in their series of 20 patients with tibial plateau fractures treated with locking compression plate fixation reported 5 patients $(25 \%)$ with type IV, $5(25 \%)$ patients with type V and 10 (50\%) with type VI fracture patterns. In our series of 20 patients, 4 (20\%) cases with type II, one (5\%) with type IV, 9 (45\%) with type $\mathrm{V}$ and $6(30 \%)$ with type VI was noted. Our series had more number of type $\mathrm{V}$ cases as compared to more number of type VI cases in their series.

Side Involved: Ryan J Krupp et al ${ }^{[44]}$ in their series of 28 patients with Tibial Condyle fractures treated by Locking plate fixation, 14 patients $(50 \%)$ had fracture of the right and 14 patients $(50 \%)$ had fracture of the left tibial condyle. In our study we had 12 patients $(60 \%)$ with right side involvement and 8 patients $(40 \%)$ with involvement of the left tibial plateau. We noticed that 10 patients who had right side involvement was following a road traffic accident, 6 patients with left side involvement was following a road traffic accident. As most of the road traffic accidents are following a two wheeler accident, the tendency of the individuals to use the right leg more and falling on the right side may be a factor for more involvement of the right side.

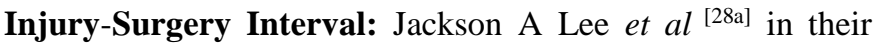
study of tibial plateau fractures treated by locking compression plate had a mean time of 12 days for surgery (range 1 day to 30 days), in our study we had a mean time of 6.35 days for surgery (range 1 day to 14 days). In our study midline incision was used in 13 cases, lateral incision was used in 6 cases, and medial incision was used in 1 case.

Post op ROM: Jackson A Lee et al ${ }^{[28 \mathrm{a}]}$ in their series of 35 patients of tibial plateau fractures treated by locking compression plate recorded an average ROM of 105 degrees. Cole et $a l^{[15 \mathrm{a}]}$ recorded a ROM of 122 degrees, Egol et al ${ }^{[20]}$ in his study had 109 degrees. Ryan J Krupp et al ${ }^{[44]}$ in their study found on a average patients had 109 degrees. In our study we had 6 patients $(30 \%)$ with full ROM, 3 patients (15\%) with 120 degrees, 4 patients $(20 \%)$ with 110 degrees, 4 with (20\%) 100 degrees and 3 patients $(15 \%)$ with less than 90 degrees. The average post Op ROM we had in our study was 112 degrees, which is comparable to the other studies. The cases who had reduction in ROM were the ones with severe soft tissue injury, which was allowed to settle down before the surgery and were taken up late for surgery, Two cases who didn't follow the protocol properly and mobilize as advised in the initial period ended with decreased ROM.

Time Required for Union: In the study by Cole et al ${ }^{[15 \mathrm{a}]}$ the average time for union and full weight bearing was 12.6 weeks in the group of 77 patients. Jackson a Lee et al [28a] found that the time for union was 4.2 months in their study of 
35 patients of Tibial plateau fractures. Ehlinger $\mathrm{M}$ et al $^{[21]}$ in their study found the average healing time was 10 weeks in 20 patients treated with locked plating in tibial plateau fractures. In our study the average time required for union was 15 weeks ranging from 12 to 30 weeks.

Overall Results: Biggi $\mathrm{F}$ et al $^{[7]}$ in their series of 58 proximal tibial fractures, treated with locking plate fixation, had $78 \%$ good to excellent results. Comparatively we had $85 \%$ good to excellent results in our series of 20 patients. Ehlinger $\mathrm{M}$ et al [21] in their series of 20 patients with tibial plateau fractures treated with locking compression plate fixation reported a mean HSS score of 93.6 in 13 patients. We in our study had an average score of 85 according to Hospital for Special Surgery, which accounts for excellent result overall. In the study by Cole et al ${ }^{[15 a]}$, seventy of 77 fractures healed without major compications (91\%). There were 2 early loses of proximal fixation, 2 non unions, 2 deep delayed infections and 1 deep peroneal nerve palsy. We in our series of 20 cases had no cases with loss of fixation, 2 cases of infection one superficial and one deep, no cases of peroneal nerve palsy. All the cases progressed to union and no nonunion was encountered in our study. Jackson A Lee et al ${ }^{\text {[28a] }}$ in their series of 35 patients of tibial plateau fractures treated by locking compression plate recorded no cases with loss of reduction, no non-union, and no cases of deep vein thrombosis. In our study there was no case with non-union, no DVT, no case with loss of reduction.

Complications: Phisitkul $\mathrm{P}$ et al ${ }^{[40]}$ in their study of complications of locking plate fixation in complex proximal tibia injuries in 37 cases found, 8 patients (22\%) with deep infections that required operative debridements. 5 of them had a hardware removal and 1 patient required a above knee amputation. Cole A et al ${ }^{[15 \mathrm{a}]}$ in their study had 2 cases $(2.6 \%)$ of delayed deep infection, out of 77 cases of proximal tibia fractures treated. Ryan J Krupp et al ${ }^{[44]}$ had one case $(3.6 \%)$ of deep infection out of 28 patients treated with locking plate.

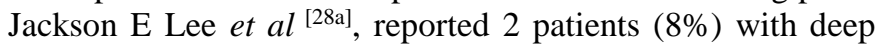
infection following fixation of tibial plateau fracture, both of them settled with wound irrigation and debridement without removing the implant which was found stable. In our study we encountered two cases (10\%) of infection, one with superficial infection, which settled with appropriate antibiotics. Deep infection occurred in 1 case, which required thorough wound debridement with implant insitu, and settled completely with appropriate antibiotics.

Egol et al ${ }^{[20]}$, in their study had significant loss of knee range of motion in 5 cases $(13.15 \%)$ out of 38 cases of tibial plateau fractures treated by locking plating. We in our study encountered 3 cases (15\%) with less than 90 degrees of ROM. Pain while walking was present in 11 cases, 8 had mild pain and 3 had moderate pain.

Ryan J Krupp et $a l^{[44]}$, in his study of 28 patients of these type $\mathrm{V}$ and VI tibial plateau fractures treated with lateral locking plate demonstrated that locking plates provided improved healing rate, restoration of the articular surface, fewer incidence of knee stiffness and reoperation, which is comparable to our study of 15 patients with these type $\mathrm{V}$ and VI injury pattern.

The limitations of our study include short-term follow-up of a small sample of patients who were treated at a single institution. But, the follow-up period was long enough to observe the primary outcome measurements of union, malunion, and short-term complications, which should be apparent in the time frame over which the study was conducted. Long-term outcomes, such as the incidence of post-traumatic arthritis, will require a more comprehensive study with long-term follow-up.

\section{Conclusion}

From our study, we conclude that

- Open/closed reduction and internal fixation of closed tibial plateau fractures with locking compression plate is an effective method of treatment provided there is no extensive soft tissue injury.

- Locking compression plate provides good angular stability with its triangular reconstruction principle.

- Locking compression plates are of great use in elderly patients with severe osteoporotic bone.

- Closed reduction and plate fixation by MIPPO is a soft tissue friendly approach in the treatment of tibial plateau fractures preserving the blood supply to the fragments.

- Even with open reduction, there is less soft tissue trauma and less post-operative stiffness.

- Non requirement of bone graft decreases the morbidity associated with donor site.

- Locking compression plates can restore the maximal joint stability and congruity, which are essential for articular cartilage regeneration.

- Early mobilization is absolutely essential in preventing the knee stiffness.

- Weight bearing should be delayed until solid union to prevent the articular collapse.

Prognosis of this complex fracture depends on

1. The degree of articular depression,

2. The extent and separation of the condylar fracture lines,

3. The degree of diaphyseal-metaphyseal comminution and

4. The integrity of the soft tissue envelope.

To conclude Locking compression plate is an invaluable implant in the treatment of tibial plateau fractures, especially when the fracture is severely comminuted and in cases of osteoporosis.

\section{References}

1. AO. Numerical Classification Muller et al. Classification of fractures Berlin springer-Verlaf 1990, 15.

2. Apley AG. Fractures of the lateral tibial condyle treated by skeletal traction and early mobilization. $\mathrm{J}$ Bone and Joint Surg. 1956; 38B:699.

3. Apley AG. Fractures of the tibial plateau. Orthop Clin North Am. 10; 61:1979.

4. Barei DP, Nork SE, Mills WJ, Henley MB, Benirschke SK. Complications associated with internal fixation of high-energy bicondylar tibial plateau fractures utilizing a two-incision technique. J Orthop Trauma. 2004; 18(10):649-57.

5. Barei DP, Nork SE, Mills WJ, Coles CP, Henley MB, Benirschke SK et al. Functional outcomes of severe bicondylar tibial plateau fractures treated with dual incisions and medial and lateral plates. J Bone Joint Surg Am. 2006; 88(8):1713-21.

6. Biyani A, Reddy NS, Chaudhury J. The results of surgical management of displaced tibial plateau fractures in the elderly. Injury. 26; 291:1995.

7. Biggi F, Di Fabio S, Antimo DC, Trevisani S. Tibial plateau fractures: internal fixation with locking plates and the MIPO technique. Injury. 2010; 41(11):1178-82.

8. Blake R, Watson JT, Morandi M. Treatment of complex 
tibial plateau fractures with the Ilizarov external fixator. J Orthop Trauma. 7; 167:1993.

9. Blokker CP, Rorabeck CH, Bourne RB. Tibial plateau fractures and analysis of treatment in 60 patients. Clin Orthop. 182; 193:1984.

10. Brown GA, Sprague BL. Cast brace treatment of plateau and bicondylar fractures of the proximal tibia. Clin Orthop. 119; 184:1976.

11. Brown TD, Anderson DD, Nepola JV. Contact stress aberrations following imprecise reduction of simple tibial plateau fractures. J Orthop Res. 1988; 6:851.

12. Bucholz RW, Carlton A, Holmes R. Interporous hydroxyapatite as a bone graft substitute in tibial plateau fractures. Clin Orthop. 1989; 240:53.

13. Canadian Orthopaedic Trauma Society, Open reduction and internal fixation compared with circular fixator application for bicondylar tibial plateau fractures. Results of a multicenter, prospective, randomized clinical trial. J Bone Joint Surg Am. 2006; 88(12):2613-23.

14. Charnley J. The Closed Treatment of Common Fractures, $3^{\text {rd }}$ ed. Baltimore, Williams \& Wilkins, 1961.

15. Cho KY, Oh HS, Yoo JH, Kim DH, Cho YJ, Kim KI. Treatment of Schatzker Type V and VI Tibial Plateau Fractures Using a Midline Longitudinal Incision and Dual Plating. Knee Surg Relat Res. 2013; 25(2):77-83.

16. Cole A Peter, Michael Zlowodzki, Philip J Kregor. Treatment of proximal tibia fractures using the less invasive stabilization system: surgical experience and early clinical results in 77 fractures. Journal of Orthopaedic Trauma. 2004; 18(8):10.

17. Decoster TA, Nepola JV. Cast brace treatment of proximal tibial plateau fractures: Ten year follow-up study. Clin Orthop 231:196, 1988.

18. Dee M, Sojka JM, Daccarett MS, Mormino MA. Evaluation of popliteal artery injury risk with locked lateral plating of the tibial plateau. J Orthop Trauma. 2011; 25(10):603-7.

19. Duwelius PJ, Rangitsch MR, Colville MR, Woll TS. Treatment of tibial plateau fractures by limited internal fixation. Clin Orthop Relat Res. 1997; (339):47-57.

20. Edwin P, Geoffrey Su, Komal Adam, David. Operative treatment of Tibial Plateau Fractures in patients older than 55 years. Clin Orthop. 2004; 421:240-248.

21. Egol KA, Su E, Tejwani NC, Sims SH, Kummer FJ, Koval KJ. Treatment of complex tibial plateau fractures using the less invasive stabilization system plate: clinical experience and a laboratory comparison with double plating. J Trauma. 2004; 57(2):340-6.

22. Ehlinger AM, Rahme AB, Moor BK, Di Marco AA, Brinkert AD, Adam AP et al. Reliability of locked plating in tibial plateau fractures with a medial component, Orthop Traumatol Surg Res. 2012; 98(2):173-9.

23. Gunasekaran Kumar, Nicholas Peterson, Badri Narayan. Bicondylar tibial fractures: Internal or external fixation. Indian J Orthop. 2011; 45(2):116-124.

24. Higgins TF, Klatt J, Bachus KN. Biomechanical analysis of bicondylar tibial plateau fixation: how does lateral locking plate fixation compare to dual plate fixation. J Orthop Trauma. 2007; 21(5):301-6.

25. Hohl M. Part 1 fractures of the proximal tibia and fibula. In: Rockwood, C. A. Green, D. Bucholz, R., EDS. Fractures in Adults, $3^{\text {rd }}$ ed. Philadelphia, J. B. Lippincott, 1991, 1725.

26. Hohl M. Tibial Condyle Fractures. J Bone Joint Surg
Am. 1967; 49:1455.

27. Hohl M, Luck V. Fractures of the tibial condyle. J Bone Joint Surg Am. 1956; 38:1001.

28. Honkonen SE. Degenerative arthritis after tibial plateau fractures. J Orthop Trauma. 1995; 9:273.

29. Honkonen SE. Indications for surgical treatment of tibial condyle fractures. Clin Orthop Relat Res. 1994; 302:199205.

30. Jackson A, Lee Stamatios A. Papadakis, Charles Moon, and Charalampos G. Zalavras. Tibial plateau fractures treated with the less invasive stabilisation system. Int Orthop, 2007, 31(3).

31. Kennedy JC, Bailey WH. Experimental tibial plateau fractures. Studies of Mechanism and a Classification. J Bone Joint Surg. 1968; 50A:1522.

32. Kettlekamp DB, Hillberry BM, Murrish DE, Heck DA. Degenerative arthritis of the knee secondary to fracture malunion. Clin Orthop. 1988; 234:159.

33. Krettek C, Gerich T, Miclau T. A minimally invasive medial approach for proximal tibial fractures. Injury, 2001, 32.

34. Lansinger O, Bergman B, Courmner L. Tibial condylar fractures: A20 year followup. J Bone Joint Surg Am. 1986; 68:13.

35. Lindeque B, Baldini $\mathrm{T}, \mathrm{A}$ biomechanical comparison of three different lateral tibia locking plates. Orthopedics. 2010; 33(1):18-21.

36. Mast J, Ganz R, Jacob R. Planning and Reduction Techniques in Fracture Surgery. Berlin, Springer-verlag, 1989.

37. McEnery KW, Wilson AJ, Pilgram TK. Fractures of the tibial plateau: Value of spiral CT coronal plane reconstruction for detecting displacement in vitro. AJR. 1994; 163:1177.

38. Mitchell N, Shepard N. Healing of articular cartilage in intra-articular fractures in rabbits. J Bone Joint Surg Am. $1980 ; 62: 628$.

39. Mueller ME, Nazarian S, Koch P. Comprehensive Classification of Fractures of Long Bones. Berlin, Springer-Verlag, 1990.

40. Mueller KL, Karunakar MA, Frankenburg EP, Scott DS, Bicondylar tibial plateau fractures: a biomechanical study. Clin Orthop Relat Res. 2003; 412:189-95.

41. Oh JK, Hwang JH. Locking plate in proximal tibial fracture: a correlation between the coronal alignment of tibia and joint screw angle. Yonsei Med J. 2013; 1:4.

42. Open Reduction Internal Fixation of Complex Proximal Tibial Fractures. Benirschke SK, Agnew SG, Mayo KA, Henley MB, Santoro VM. J Orthop Trauma. 1991; 5:236.

43. Phisitkul P, McKinley TO, Nepola JV, Marsh JL. Complications of locking plate fixation in complex proximal tibia injuries. J Orthop Trauma. 2007; 21(2):8391.

44. Rafi M, Firooznia H, Golimba C. Computed tomography of tibial plateau fractures. AJR. 1984; 142:181.

45. Rasmussen P. Tibial condylar fractures, impairment of knee joint stability as an indicator for surgical treatment. J Bone Joint Surg Am. 1973; 55:1331.

46. Roberts JM. Fractures of the Condyles of the tibia. J Bone Joint Surg. 1968; 50A:1505.

47. Ryan J, Krupp MD, Arthur L, Malkani MD, Craig S, Roberts MD. David Seligson, MD; Charles H. Crawford III, MD; Langan Smith, BS, Treatment of Bicondylar Tibia Plateau Fractures Using Locked Plating Versus External Fixation, Orthopedics. 2009; 32:8. 
48. Salter R, Simmonds DF, Malcolm BW. The biological effects of continuous passive motion on the healing of full thickness defects in articular cartilage: An experimental investigation in the rabbit. J Bone Joint Surg Am. 1980; 62:1232.

49. Sarmiento A, Kinnman PB, Latta LL. Fractures of the proximal tibia and tibial condyle: A clinical and laboratory comparative study. Clin Orthop. 1979; 145:136.

50. Savoie FH, Vander Griend RA, Ward EF, Hughes JL. Tibial plateau fractures: A review of operative treatment using AO technique. Orthopaedics. 1987; 10:745.

51. Schatzker J, McBroom R. Tibial plateau fractures: The Toronto experience 1968-1975. Clin Orthop. 1979; 138:94.

52. Schulak DJ, Gunn DR. Fractures of the Tibial Plateau: A Review of the Literature. Clin Orthop 1975; 109: 166.

53. Spagnolo R, Pace F. Management of the Schatzker VI fractures with lateral locked screw plating. Musculoskelet Surg, 2011, 27.

54. Spiegel PG, Shybut GT. Tibial plateau fractures. Editorial. Clin Orthop. 1979; 183:12.

55. Tian K, Duanmu QL, Ni LZ, Huang DH, Mei ZF. Surgical treatment of tibia plateau fractures with external fixator and the locking plate. Zhongguo Gu Shang. 2009; 22(8):618-20.

56. Tscherene $\mathrm{H}$, Lober hoffer $\mathrm{P}$. Tibial plateau fracture management and expected result CORR. 1993; 292: 87100.

57. Waddell AP, Johnston DWC, Neidre A. Fractures of the tibial plateau: A review of 95 patients and comparison of treatment methods. J Trauma. 1981; 21:376.

58. Watson JT. High energy fractures of the tibial plateau. Orthop Clin North Am. 1994; 25:728.

59. Weaver MJ, Harris MB, Strom AC, Smith RM, Lhowe D, Zurakowski D et al. Fracture pattern and fixation type related to loss of reduction in bicondylar tibial plateau fractures. Injury. 2012; 43(6):864-9.

60. Weber WW, Neckmenn CH, Berakos JA. Lateral Tibial rim (Segond) fracture-MRI characteristics radiology. $1991 ; 180: 731-734$.

61. Weiner LS, Kelley M, Yang E. The use of combination internal fixation and hybrid external fixation in severe proximal tibia fractures. J Orthop Trauma. 1995; 9:244.

62. Wirth CR. Meniscus repair-CORR. 1991; 157:153.

63. Yoo BJ, Beingessner DM, Barei DP. Stabilization of the posteromedial fragment in bicondylar tibial plateau fractures: a mechanical comparison of locking and nonlocking single and dual plating methods. J Trauma. 2010; 69(1):148-55.

64. Young MJ, Barrack RL, Complications of internal fixation of tibial plateau fractures. Orthop Rev. 1994; 23(2):149-54.

65. Yu Z, Zheng L, Zhang Y, Li J, Ma B. Functional and radiological evaluations of high-energy tibial plateau fractures treated with double-buttress plate fixation. Orthopedics Oncology Institute of Chinese PLA, Tangdu Hospital, Republic of China.

66. Zhang Y, Fan DG, Ma BA, Sun SG. Treatment of complicated tibial plateau fractures with dual plating via a 2-incision technique. Orthopedics, 2012, 35(3). 